\title{
Get in touch with safety in health
}

\author{
Gerald Sendlhofer ${ }^{1,2^{*}}$ and Lars Peter Kamolz ${ }^{2}$
}

\author{
Keywords: Patient Safety, Quality and Process \\ Management, Simulation and Training, Health economic \\ aspects
}

\section{Editorial}

Healthcare systems have always striven to avoid errors and to have safe procedures in place. The European Commission estimated that in member states, between $8 \%$ and $12 \%$ of patients admitted to hospital suffer from adverse events while receiving care [1]. In 1999, the publication of 'to err is human' suggested a comprehensive approach in improving patient safety [2] and explored the need to enhance knowledge and tools to improve safety. In the meantime, patient safety activities have started around the world [3]. Subsequently, patient safety has received considerable attention and is fast becoming an important research area [4].

Patient safety is linked to human errors and the risk assessment approach of the aviation industry has provided healthcare with some best practice examples on dealing with this systematically. For example, checklists, team training, and incident reporting have been widely implemented in healthcare systems worldwide. Following the introduction of the WHO-Surgical Safety Checklist by Gawande in 2009 several comprehensive studies have evaluated its use [5]. The findings of these studies indicate that even where there is an evidence-base demonstrating a benefit from the use of such tools, this does not guarantee acceptance and appropriate use by healthcare professionals $[6,7]$. The reasons for this can lie in a lack of positive role models, hierarchical barriers, limited methodological knowledge and inappropriate implementation procedures [8].

It is obvious that patient safety is linked to a broad spectrum of challenges and needs to include a variety of interventions in order to succeed. The WHO and the European Commission as well as other official bodies have suggested implementing national strategies to

\footnotetext{
* Correspondence: gerald.sendlhofer@klinikum-graz.at

'Department of Quality and Risk Management, University Hospital Graz, Graz, Styria, Austria

${ }^{2}$ Division of Plastic, Aesthetic and Reconstructive Surgery, Department of Surgery, Medical University Graz, Graz, Styria, Austria
}

address the key issues relating to the improvement of patient safety (Table 1) [9]. This includes fields of intervention such as organizational, policy and personnel developments, monitoring measures and measures to raise public awareness. Furthermore, within the healthcare system we have to consider environmental, cultural, professional and healthcare financing differences. To enable these national strategies the establishment of

I. clinical risk management strategies,

II. the implementation of health promotion schemes and

III. the development of safe and user-friendly systems, processes and tools

for patient safety accompanied by information and communication technologies are needed [10]. All of these measures will help to support comprehensive changes that develop safe procedures in healthcare systems.

Patient safety is an international imperative and is fundamental to healthcare policy, planning, organization, delivery, evaluation and quality improvement. However, investment in patient safety research and outstanding research goals by healthcare organizations and by governments are lacking. As described by Shojania [11], three distinct achievements have to occur in order to show progress in patient safety:

I. Identification of interventions that reduce common types of adverse events,

II. Dissemination of these effective interventions into routine practice, and

III. Development of tools to measure improvements in patient safety issues.

For this reason, the journal Safety in Health pays particular attention to global trends in healthcare that affect patient safety. The journal has four dedicated sections. Research in the section Patient Safety mainly focuses on studies of patient safety showing evidence in implementation and effectiveness in primary care, ambulatory care, hospitals, care transitions at hospital discharge and 


\section{Table 1 WHO - 10 Facts on patient safety}

\begin{tabular}{ll}
\hline 1 & Patient safety is a serious global public health issue \\
2 & One in 10 patients may be harmed while in hospital \\
4 & Hospital infections affect 14 out of every 100 patients admitted \\
5 & Most people lack access to appropriate medical devices \\
6 & Delivery of safe surgery requires a teamwork approach \\
7 & About $20 \%$ - $40 \%$ of all health spending is wasted due to \\
8 & A poor-quality care \\
9 & Patient and community engagement and empowerment are key \\
10 & Hospital partnership can play a critical role
\end{tabular}

Source: http://www.who.int/features/factfiles/patient_safety/patient_safety_facts/en/ Accessed 11-Nov-2014.

home care. It includes the development of new validated tools and measures which fit with patient safety issue. Critical incidents including possible solutions and explorations of patient involvement in decision-making, selfmanagement, error prevention and evaluating the effect on patient safety are of particular interest [12].

Within the section Training and Simulation, we especially explore the vast need to contribute essentials in healthcare education; for example, how to train and assess students, and all healthcare professionals, in an era where limited faculty teaching time and technological progress in diagnosis and treatment is apparent. Specializations in skills, and the need for a "super specialists" approach in interdisciplinary teams, require validated methods to ensure the effectiveness of simulation and training to best support healthcare professionals and patients [13].

The section Quality and Process Management will include scientific articles addressing setting new standards in quality management to discuss new regulations, as well as the implementation, maintenance and validation of quality management systems. In process management, the issue of critical pathways describing the optimal sequencing and timing of interventions is the key as they have great impact on patient safety and quality of care [14].

Achieving high value for patients must become the overarching goal of healthcare delivery, where value is defined as the health outcomes achieved per expense [15] and is the focus of the section entitled Health Economic Aspects. It is related to the efficiency, effectiveness, value and behavior of the economics of health and includes topics such as financing of health services and policy interventions, as these topics greatly influence patient safety in healthcare. As described by Porter, if values improve, patients, payers, providers, and suppliers can all benefit while the economic sustainability of healthcare increases [15].

Taken together, we strongly believe that this new journal will have an impact within the scientific community. It aims to disseminate the latest research on safety in healthcare and to provide an international forum for academics, clinicians, and healthcare managers to discuss needs and trends. Safety in Health will accept outstanding research and welcome editorials, research articles, reviews, case reports, case studies, commentaries, database articles, letters to the editor, methodology articles and short reports on topics relating to quality and safety in healthcare.

\section{Competing interests}

The authors declare that they have no competing interests.

\section{Acknowledgements}

The authors wish to express their gratitude to BioMed Central who was greatly attracted by the idea to start a new journal.

Received: 19 November 2014 Accepted: 19 February 2015 Published: 27 May 2015

\section{References}

1. Council Recommendation of 9 June 2009 on patient safety, including the prevention and control of health care associated infections. Off J Eur Union. 2009;151:01. http://ec.europa.eu/health/patient_safety/docs/council_2009_ en.pdf accessed May-13-2015

2. Kohn LT, Corrigan J, Donaldson MS. To err is human: building a safer health system. Washington, DC: National Academy Press; 1999.

3. Exploring patient participation in reducing health-care-related safety risks. Europe: Word Health Organization; 2013. ISBN ISBN:978-92-890-0294-3. http://www.euro.who.int/__data/assets/pdf_file/0010/185779/e96814.pdf accessed May-13-2015.

4. Sendlhofer G, Brunner G, Tax C, Falzberger G, Smolle J, Leitgeb K, et al. Systematic implementation of clinical risk management in a large university hospital: the impact of risk managers. Wien Klin Wochenschrift. 2015;127:1-11. doi:10.1007/s00508-014-0620-7.

5. Haynes AB, Weiser TG, Berry WR, Lipsitz SR, Breizat A-HS, Dellinger EP, et al. A Surgical Safety Checklist to Reduce Morbidity and Mortality in a Global Population. N Engl J Med. 2009;360:491-9.

6. Berger MS, Wachter RM, Greysen SR, Lau CY. Changing our culture to advance patient safety. J Neurosurgery. 2013;119(6):1359-69.

7. Sendlhofer G, Mosbacher N, Leitgeb K, Kober B, Jantscher L, Berghold A, et al. Implementation of a surgical safety checklist: interventions to optimize the process and hints to increase compliance. PLoS One. 2015;10(2), e0116926. doi:10.1371/journal.pone.0116926.

8. Conley DM, Singer SJ, Edmondson L, Berry WR, Gawande AA. Effective surgical safety checklist implementation. J Am Coll Surg. 2011;212(5):873-9.

9. Word Health Organization. http://www.who.int/features/factfiles/ patient_safety/patient_safety_facts/en/ Accessed 13-May-2015.

10. Federal Ministry for Health. Nationwide Patient Safety Strategy for Austria 2013 - 2016. Vienna: Commissioned by the Federal Ministry of Health; 2013. http://bmg.gv.at/cms/home/attachments/1/4/5/CH1331/ CMS1366277814203/patsistr__engl.pdf Accessed 13-May-2015.

11. Shojania KG, Thomas EJ. Trends in adverse events over time: why are we not improving? BMJ Qual Safe. 2013;22:273-7.

12. Agency for Healthcare Research and Quality. Making health care safer II: an updated critical analysis of the evidence for patient safety practices. Evidence Report/Technology Assessment Number 211. 2014. http:// www.ahrq.gov/research/findings/evidence-based-reports/services/quality/ ptsafetyll-full.pdf accessed Nov-01-2014.

13. Issenberg SB, Scalese RJ. Simulation in health care education. Perspect in Biol Med. 2008;51(1):31-46. doi: 10.1353/pbm.2008.0004.

14. Coffey RJ, Richards JS, Remmert CS, LeRoy SS, Schoville RR, Baldwin PJ. Quality management in health care: an introduction to critical paths. Fall 1992, Aspen Publisher, Inc; 1992.

15. Porter ME. What is value in health care? N Engl J Med. 2010;363(26):2477-81.

doi:10.1186/2056-5917-1-1

Cite this article as: Sendlhofer and Kamolz: Get in touch with safety in health. Safety in Health 2015 1:1. 